\title{
Sex difference in mouse embryonic development at neurulation
}

\author{
M. J. Seller and K. J. Perkins-Cole \\ Paediatric Research Unit, The Prince Philip Research Laboratories, \\ United Medical \& Dental Schools of Guy's \& St Thomas' Hospitals, Guy's Tower, 7th Floor, \\ London Bridge, London SEI 9RT, U.K.
}

\begin{abstract}
Summary. Sixty-seven mouse embryos from 10 litters collected on the morning of Day 9 of gestation, when neurulation is beginning, were classified according to the precise stage of development reached, and sex-chromatin analysis was performed on the yolk sac. Within litters, the least developed embryos were more likely to be female than male, while the most advanced embryos were predominantly male. Taking all embryos, the mean somite number was greater in males than females.
\end{abstract}

\section{Introduction}

In polytocous species such as the mouse, it is recognized that in early embryos, within litters, there is variation in the stage of development reached at any one time. Several factors could account for this, including the time after ovulation at which fertilization occurs, rate of oviducal transport and time of onset of blastocyst implantation, as well as individual variation in the rate of cleavage. Hafez (1962) using rabbits and Gates (1965) using mice identified what they termed fast- and slowcleaving early embryos from within litters and separately transplanted them into foster mothers. The former gave more offspring, and so were considered to be more viable than the latter. Tsunoda et al. (1985) in a similar experiment in mice found altered sex ratios in the two groups, fast cleavers having an excess of males, and slow cleavers more females.

Because of an interest in neural tube defects in man, a developmental abnormality which affects females more often, and more severely, than males, we have examined litters of mouse embryos around the time of neurulation to see whether there is a sex difference in the developmental stage reached.

\section{Materials and Methods}

Male and female CBA/Gr-ct/ct mice were mated overnight and checked each morning for vaginal plugs. The curly tail mutation produces spina bifida or a curled tail in about $60 \%$ of the offspring (Grüneberg, 1954; Embury et al., 1979). On the morning of Day 9 of pregnancy (day of vaginal plug = Day 1), the females were killed. The conceptuses were removed from the uterus and each was placed in its own numbered watchglass in Medium TC199 with Hepes (Flow Laboratories, Rickmansworth, Herts WD3 IPQ, U.K.), and treated separately throughout. Under the binocular microscope each embryo was carefully dissected from its membranes and set aside, and the yolk sac isolated. The developmental stage of the embryo was assessed by counting the number of somites and also by making a sketch of it. The yolk sac was fixed and processed for sex chromatin analysis by the method of Evans et al. (1972). The slide preparations were stained with orcein, coded and scored on two separate occasions for the presence or absence of a sex chromatin mass on the nuclear membrane. Embryos for which $40 \%$ or more of the cells appeared sex-chromatin positive were regarded as female and those for which $<5 \%$ of the cells were recorded as positive were scored as male.

Separately, and before the results of the sex chromatin analysis were known, the individuals of each litter of embryos were arranged in ascending order of developmental maturity. They were then separated into three groups - the least mature developmental stage reached, the most advanced stage reached and intermediate stages. In some litters, a single embryo was at either extreme of development, while in others, there were two or more which were 
equally the least, or the most, mature. The relative number of males and females in each group was determined and compared. Finally, the mean somite number of all males and females in the study was calculated and compared. Statistical analysis of results was performed using a $\chi^{2}$ test on actual numbers obtained.

\section{Results}

There were 10 litters from which 67 embryos were obtained. Individual litter sizes range from 3 to 10 (Table 1). In addition, there were 3 empty gestational sacs. Table 1 also shows that there was a range of developmental stages within litters, from a minimum difference of 4 somites and a maximum difference of 10 somites between the least and most developed.

Table 1. Range of embryonic developmental stages on Day 9 of gestation within litters according to somite numbers

\begin{tabular}{lcc}
\hline $\begin{array}{l}\text { Litter } \\
\text { no. }\end{array}$ & $\begin{array}{c}\text { No. of } \\
\text { embryos }\end{array}$ & $\begin{array}{c}\text { Range of } \\
\text { somite number }\end{array}$ \\
\hline 1 & 8 & All pre-somite \\
2 & 3 & $1-6$ \\
3 & 3 & $2-7$ \\
4 & 9 & $5-12$ \\
5 & 7 & $0-7$ \\
6 & 8 & $0-10$ \\
7 & 3 & $0-5$ \\
8 & 8 & $0-8$ \\
9 & 10 & $4-8$ \\
10 & 8 & $0-6$ \\
\hline
\end{tabular}

When the embryos were classified according to their maturity (Table 2), 12/16 (75\%) of the least developed were female, while only $1 / 18(5.5 \%)$ of the most advanced were female. Females comprised $18 / 33(55 \%)$ of the intermediate group. Overall, $31 / 67(46 \%)$ of the total embryos were female. The shift towards females in the least mature group, and away from females in the most mature group was statistically significant when compared with all females in the study $\left(\chi^{2}=4 \cdot 27\right.$, 1 d.f., $P<0.05$ for the least developed, $\chi^{2}=10.02$, 1 d.f., $P<0.005$ for the most mature). That for the intermediate group was not significantly different $\left(\chi^{2}=0 \cdot 70,1\right.$ d.f., $\left.P>0 \cdot 3\right)$.

One litter was excluded from the somite analysis because all of the embryos were at the presomite stage. In the remaining 9 litters, the average somite number for male embryos was $6 \cdot 2$ (range 0-12) and that for females was 3.7 (range 0-8).

Table 2. Number of male and female embryos on Day 9 of gestation according to developmental status

\begin{tabular}{|c|c|c|c|c|c|c|c|c|}
\hline & \multicolumn{8}{|c|}{ Embryonic developmental category } \\
\hline & \multicolumn{2}{|c|}{ Least mature } & \multicolumn{2}{|c|}{ Intermediate } & \multicolumn{2}{|c|}{ Most mature } & \multicolumn{2}{|c|}{ Total } \\
\hline & Male & Female & Male & Female & Male & Female & Male & Female \\
\hline $\begin{array}{l}\text { No. of } \\
\text { embryos } \\
\% \text { Females }\end{array}$ & 4 & $\begin{array}{l}12 \\
75\end{array}$ & 15 & $\begin{array}{l}18 \\
55\end{array}$ & 17 & $\begin{array}{l}1 \\
5 \cdot 5\end{array}$ & 36 & $\begin{array}{l}31 \\
46\end{array}$ \\
\hline
\end{tabular}




\section{Discussion}

In the mice investigated in this study, it was found that on Day 9 of gestation, when neurulation and somite formation are beginning, there is a range of developmental stages within litters, and there is a sex difference in the stage attained. Females are less developed on the whole and males are more developed. On average at this time, males have two somites more than females.

Since the mice used in the study bear a particular mutation which predisposes to neural tube defects, it is possible that the findings represent an effect of the gene. However, the same sexual inequality in developmental speed has been observed using other methods in another strain of mice, at the blastocyst stage (Tsunoda et al., 1985) and by implication in rats later, on Day 12, when male embryos weighed more than females and had a greater absolute protein content (Scott \& Holson, 1977). Moreover, P. Burgoyne (personal communication) has observed that male and female mouse embryos start cleaving at the same time, but by the blastocyst stage males are more advanced than females.

The rate of preimplantation development in the mouse is governed by genes both within the $\mathrm{H}-2$ complex and located elsewhere. Alleles of an $\mathrm{H}-2$-associated gene produce either fast or slow development (Goldbard \& Warner, 1982), but transfer of the gene to different genetic backgrounds shows that its expression is modified by other genes in the genome. The sex effect on the speed of development observed in the present study and by others appears to be over and above this, because the sex effect occurs within litters and the other genetic effect occurs between litters. The fact that the sex effect is manifest before gonadal differentiation suggests the possibility of sex-linked genes controlling the rate of cell division.

It has long been known that many of the common congenital abnormalities in man, like neural tube defects and cleft lip and palate, have a preponderance in one sex or the other. This has been a source of puzzlement since organogenesis largely precedes gonadogenesis. The present findings suggest a possible mechanism since they show that there is an observable sexual difference at the time of organogenesis. The aetiology of most of the human congenital malformations is multifactorial with genetic and environmental factors contributing to the cause. If males are developing quicker than females, they will be exposed to the environmental influence for a shorter time than females and so a differential effect between the sexes could result, producing malformations in females rather than males. The present work suggests that at least one route whereby the genetic component exerts its effect on malformations could be through regulating the speed of cleavage and early embryonic development.

We thank Dr Paul Burgoyne and Mr John Crolla for technical advice and the Medical Research Council for generous financial assistance.

\section{References}

Embury, S., Seller, M.J., Adinolfi, M. \& Polani, P.E. (1979) Neural tube defects in curly-tail mice. I. Incidence, expression and similarity to the human condition. Proc. R. Soc. B 206, 85-94.

Evans, E.P., Burtenshaw, M.D. \& Ford, C.E. (1972) Chromosomes of mouse embryos and newborn young: preparations from membranes and tail tips. Stain Technol. 47, 229-234.

Gates, A.H. (1965) Rate of ovular development as a factor in embryonic survival. In Preimplantation Stages of Pregnancy (Ciba Fdn Symposium), pp. 270-288. Ed. G. E. W. Wolstenholme. Churchill, London.

Goldbard, S.B. \& Warner, C.M. (1982) Genes affecting the timing of early mouse embryo development. Biol. Reprod. 27, 419-424.
Grüneberg, H. (1954) Genetical studies on the skeleton of the mouse VIII curly-tail. J. Genet. 52, 52-67.

Hafez, E.S.E. (1962) Differential cleavage rate in 2-day litter mate rabbit embryos. Proc. Soc. exp. Biol. Med. $110,142-145$.

Scott, W.J. \& Holson, J.F. (1977) Weight differences in rat embryos prior to sexual differentiation. $J$. Embryol. exp. Morph. 40, 259-263.

Tsunoda, Y., Tokunaga, T. \& Sugie, T. (1985) Altered sex ratio of live young after transfer of fast- and slow-developing mouse embryos. Gamete Res. 12. 301-304. 